\title{
Correction to: Exploring the Dynamics of Social Networks in Urban Informal Settlements: the Case of Mathare Valley, Kenya
}

\section{Christian Morgner ${ }^{1} \cdot$ Amollo Ambole $^{2} \cdot$ Christer Anditi $^{3} \cdot$ Daniel Githira $^{4}$}

Published online: 7 July 2020

(C) Springer Nature B.V. 2020

\section{Correction to: Urban Forum \\ https://doi.org/10.1007/s12132-020-09389-2}

The original version of this article unfortunately contains mistakes introduced during the production phase. The Fig. 7 was incorrectly captured. The corrected Fig. 7 is shown in the next page.

The original article has been corrected.

Publisher's Note Springer Nature remains neutral with regard to jurisdictional claims in published maps and institutional affiliations.

The online version of the original article can be found at https://doi.org/10.1007/s12132-020-09389-2

Christian Morgner

cm570@1e.ac.uk

1 University of Leicester, Leicester, UK

2 University of Nairobi, Nairobi, Kenya

3 Stellenbosch University, Stellenbosch, South Africa

4 Nairobi, Kenya 

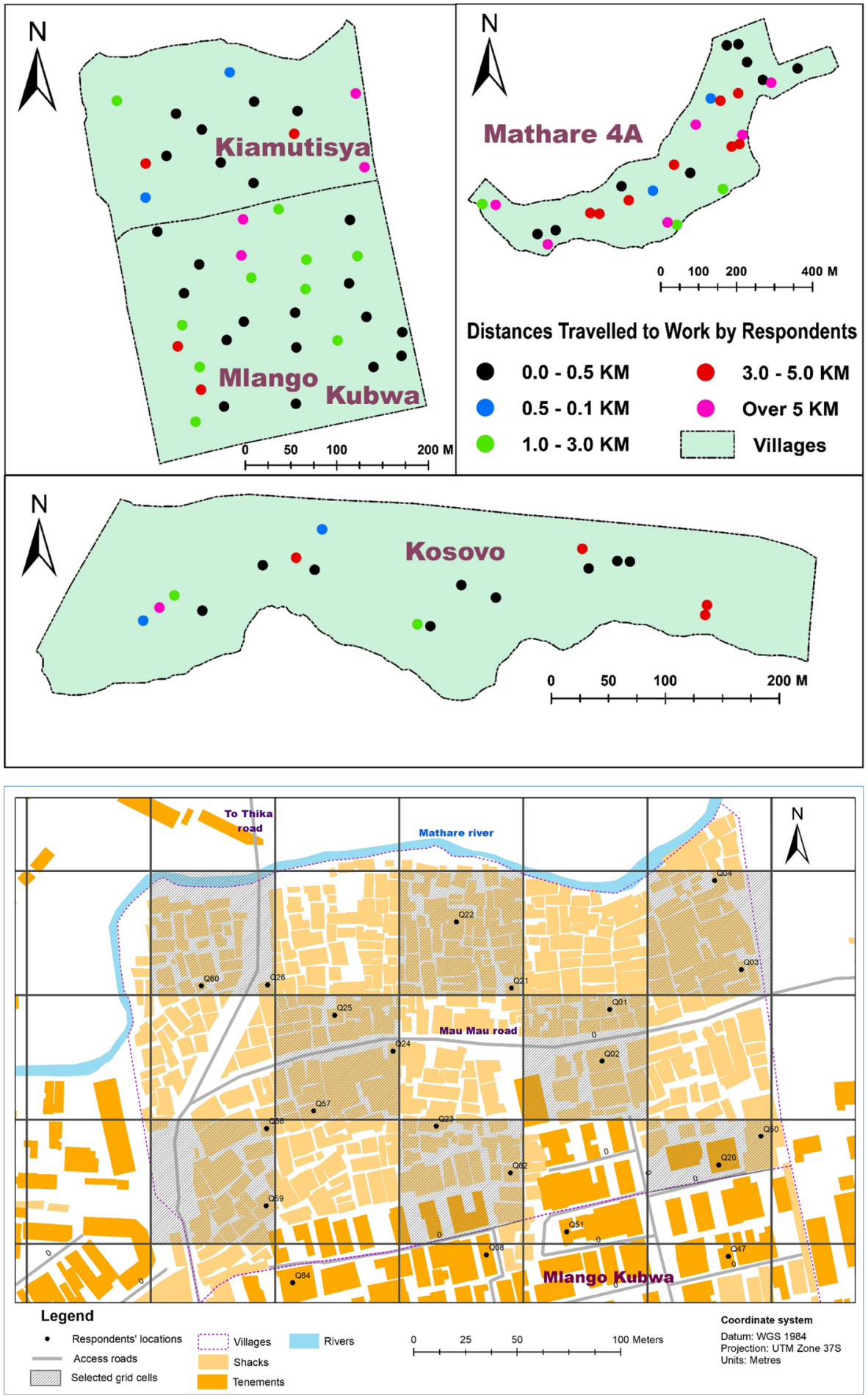

Fig. 7 Analysis of distances from respondents' home to work (Map and Chart Illustrations) (Source: Authors) 